\title{
Tissue stiffness in BPH patients from magnetic resonance elastography
}

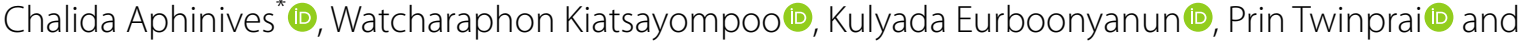 \\ Saranya Jaruchainiwatio
}

\begin{abstract}
Background: BPH is commonly found in older men which can lead to lower urinary tract symptoms. Magnetic resonance elastography (MRE) is an innovative, noninvasive imaging technique used to evaluate tissue stiffness. There has not been any study, however, that assessed the tissue stiffness in patients with BPH. A prospective descriptive study was performed to demonstrated MRI and MRE techniques of the prostate gland in ten patients with BPH to assess tissue stiffness, features of BPH on MRI and components of BPH in the area of increased stiffness.

Results: MRI and MRE examinations in all patients were successful without any complications. The mean tissue stiffness of the whole prostate gland was $4.40 \pm 0.71 \mathrm{kPa}$ with good reproducibility (ICC 0.82). Stromal components and mixed glandular-stromal components tended to be associated with the areas of increased stiffness on stiffness images, 50.6\% for stromal components and 37.9\% for mixed glandular-stromal components. Some MRI findings were seen on the patients with high mean stiffness values such as prostatic calcification, type-5 BPH pattern and large prostate volumes.
\end{abstract}

Conclusions: Prostate MRE is a useful noninvasive reproducible diagnostic tool for evaluating prostate tissue stiffness by both qualitative and quantitative assessments. The mean prostate tissue stiffness from MRE in patients with BPH in this study was $4.40 \pm 0.71 \mathrm{kPa}$. Some MRI features might be associated with increased tissue stiffness.

Trial registration: PID 229. Registered 4 October 2019. http://md.redcap.kku.ac.th

Keywords: BPH, MRE, Tissue stiffness, Shear wave, Noninvasive

\section{Introduction}

Benign prostatic hyperplasia (BPH) is a condition commonly found in older men. It can be found in $50-60 \%$ of men by the age of 60 [1] and can lead to lower urinary tract symptoms (LUTS), including voiding and storage symptoms. About $90 \%$ of men aged between 45 and 80 have at least one LUTS [2].

$\mathrm{BPH}$ can be divided into two main components; glandular and stromal enlargements [3]. Glandular enlargement mainly leads to an increase in the prostate gland's size, resulting in obstructive symptoms. In contrast,

*Correspondence: chalida.aphinives@gmail.com

Department of Radiology, Faculty of Medicine, Khon Kaen University, 123

Group 16, Mittraparp Rd, Muang 40002, Khon Kaen Province, Thailand stromal enlargement leads to increased resistance of prostatic parenchyma, which is known as the dynamic effect [4]. BPH initially occurs in the periurethral gland (PUGs) and then continues to the transition zone (TZ), which is the main site of BPH [5]. Although BPH mainly develops in TZ and PUGs, it can also affect the peripheral zone [6]. Randall et al. classified patterns of BPH according to their MRI appearances into eight types [7].

The Prostate Imaging Reporting and Data System (PIRADS) has recommended that the measurement of the maximum AP and longitudinal diameters should be made on the mid-sagittal T2W image, and the measurement of the maximum transverse diameter should be made on the axial T2W image [8]. The size of the prostate gland can be used to determine the treatment options. 
Magnetic resonance imaging (MRI) is frequently used for the detection and risk stratification of clinically significant prostate cancer (csPCa) because of its higher resolution than other modalities [9]. BPH patients would be requested for MRI assessment when they have an abnormally high prostate-specific antigen (PSA) level or clinical suspicion of prostate cancer [10].

Magnetic resonance elastography (MRE) is an innovative, noninvasive imaging technique. It can provide information about the biomechanical properties of soft tissue and quantitative assessment based on different stiffnesses between healthy and diseased tissues. The most widely used application of the MRE is detecting and staging liver fibrosis, which is currently performed in more than 100 centers worldwide [11].

Many recent studies have assessed the utility of MRE in other organs such as the brain, muscle, and breast [12-15]. Only a few studies have assessed the utility of MRE in the prostate gland.

Kemper et al. assessed the feasibility of MRE in the prostate gland of seven healthy volunteers, using an external driver attached to the pubic bone on a $1.5 \mathrm{~T}$ scanner at a vibration frequency of $85 \mathrm{~Hz}$, and found that the prostate gland had significantly higher stiffness than the adjacent fat tissue [16]. After that Sahebjavaher et al. studied MRE using $3.0 \mathrm{~T}$ scanner and transperineal electromechanical transducer at a frequency of $70 \mathrm{~Hz}$ in six healthy volunteers and found a higher shear stiffness of the central and transition zones than the peripheral zone [17]. According to the study of Dittmann et al. to assess the elasticity of prostate gland in 12 healthy volunteers using MRE and three externally placed pressurized-air drivers at vibration frequencies of 60,70 , and $80 \mathrm{~Hz}$, there were no significant differences of values of shear wave speed between the peripheral zone and the central gland. They also assessed MRE in patients with prostate cancer and found no significant differences in shear wave speed from those of healthy volunteers. In two prostate cancer patients, however, there were areas of obviously increased stiffness that were distinct from the remaining prostate tissue [17].

There has not been any study that assessed the tissue stiffness in patients with benign prostatic hyperplasia. Therefore, a prospective descriptive study to demonstrate the technical feasibility of prostate MRE using an external air driver and assess the stiffness of prostate tissue along with MRI features of the enlarged prostate gland in patients with $\mathrm{BPH}$ was conducted.

\section{Materials and methods}

\section{Ethical consideration}

This study was a prospective descriptive study from November 2019 to October 2020. The study protocol was approved by the Ethics Committee for Human Research.

\section{Study population}

The inclusion criteria were (1) clinical or MRI features of $\mathrm{BPH}$, (2) PIRADS (v. 2.1) score 1 or 2.

The exclusion criteria were (1) prostate cancer (2) MRI artifacts that would affect an imaging interpretation.

Ten patients were enrolled in the study. Written informed consent was obtained from all the subjects.

\section{Hardware and data acquisition}

All examinations were performed in a 3.0-Tesla MRI scanner (Achieva dStream, software version 5.6.1.0, Philips Healthcare) using a phased-array surface coil. To perform MRE and generate mechanical waves, a pneumatic system that incorporated an active driver (placed outside the scan room) for producing continuous acoustic wave motion was used. A passive driver was placed against the body surface superficial to the pubic symphysis to induce shear waves traversing the prostate gland. An air-filled plastic tube was used for transmitting the pneumatic excitations from the active to the passive driver. A small soft pad was also placed beneath the passive driver to decrease the patient's vibrating sensation. The patient placed in the supine position, then a small soft pad and a passive driver are placed over the pubic symphysis. The passive driver and the pelvis were wrapped together by a kidney belt to ensure direct contact of the driver with the body surface. Finally, an anterior surface coil was set up before performing an MRI examination. A repetition frequency of the drivers at $60 \mathrm{~Hz}$ was used for the MRE study.

Prostate MRI was performed using the routine prostate protocol as demonstrated in Table 1. A gadolinium-based contrast was administered if there were no contraindications.

To image the shear waves and measure the propagation of the mechanical waves inside the tissue from the MRE, a 2D Phase Contrast Fast Field Echo (FFE) with motionencoding gradients and a 15-s breath-hold per slice was applied. Depending upon the prostate gland size, two to five axial slices through the whole prostate gland were generally obtained to generate MRE images. Before imaging the shear wave, axial $\mathrm{T} 2 \mathrm{~W}$ images were acquired to position the prostate gland and to be used as an anatomical reference. Each wave image slice was acquired at eight evenly spaced time points. The MRE protocol is shown in Table 2. The MRE examination was repeated once without repositioning the patient or the actuators to assess reproducibility.

\section{Data post-processing}

Post-processing of the images displaying wave images, FFE/Modulus images and stiffness images was performed 
Table 1 MRI protocol

\begin{tabular}{|c|c|c|c|c|c|c|c|}
\hline Sequence & TR & TE & FA & Thickness/gap & FOV & Matrix & NEX \\
\hline Coronal T2W GRE & 2.8 & 1.41 & 60 & $6 /-3$ & 360*360 (Entire pelvis) & $232 * 228$ & 1 \\
\hline Sagittal T2W & 3360 & 100 & & $3 / 0$ & $170^{*} 170$ (Entire prostate gland) & $284 * 233$ & 1 \\
\hline Coronal T2W & 2500 & 100 & & $3 / 0$ & $180^{*} 180$ (Entire prostate gland) & $256 * 239$ & 1 \\
\hline Axial T2W & 3561 & 100 & & $3 / 0$ & $160^{*} 160$ (Entire prostate gland) & $268^{*} 217$ & 2 \\
\hline Axial T2FS & 4000 & 75 & & $3 / 0$ & $160 * 160$ (Entire prostate gland) & $268^{*} 235$ & 2 \\
\hline Axial T1W & 587 & 10 & & $3 / 0$ & $160 * 160$ (Entire prostate gland) & $268 * 225$ & 1 \\
\hline $\begin{array}{l}\text { Axial DWI and ADC map using b-value of 0,800, } \\
1000 \text { and } 1500 \mathrm{~s} / \mathrm{mm}^{2}\end{array}$ & 4472 & 68 & & $3 / 0$ & $180^{*} 180$ (Entire prostate gland) & $92^{*} 101$ & 4 \\
\hline Axial T1W & 654 & 10 & & $6 / 1$ & 360*360 (Entire pelvis) & $360 * 239$ & 1 \\
\hline Axial T2W & 2651 & 110 & & $6 / 1$ & 360*360 (Entire pelvis) & $300 * 300$ & 1 \\
\hline DCE in axial plane with a temporal resolution of $8 \mathrm{~s}$ & 4.9 & $1.95 / 3.3$ & 10 & 3 & $180^{*} 200$ (Entire prostate gland) & $144^{*} 160$ & 1 \\
\hline T1FS post Gd on axial plane & 572 & 8 & & $3 / 0$ & 360*320 (Entire pelvis) & $276^{*} 207$ & 1 \\
\hline T1FS post Gd on coronal plane & 600 & 10 & & $3 / 0$ & $180 * 180$ (Entire prostate gland) & $256^{*} 198$ & 1 \\
\hline T1FS post Gd on sagittal plane & 772 & 16 & & $3 / 0$ & $170 * 170$ (Entire prostate gland) & $256^{*} 177$ & 2 \\
\hline
\end{tabular}

Table 2 MRE protocol

\begin{tabular}{ll}
\hline Field of view & $360 \mathrm{~mm} \times 318 \mathrm{~mm}$ \\
Matrix & $240 \times 82$ \\
ACQ voxel size & $1.5 \times 4.5 \mathrm{~mm}$ \\
Slice thickness & $10 \mathrm{~mm}$ \\
No. of slices & $2-5$ slices (depending on \\
& the size of prostate gland) \\
Flip angle & $30^{\circ}$ \\
TR & 50 \\
TE & 20 \\
Breath-hold & $15 \mathrm{~s}$ \\
\hline
\end{tabular}

using MREView software (software version 5.6.1.0, Philips Healthcare) (Fig. 1). The regions of interest (ROIs) for the whole prostate were drawn manually on axial FFE/Modulus images by an MRI technologist to measure tissue stiffness (Fig. 2). Each pixel on an MRE image was processed by the software and converted into stiffness values. All pixels in the ROI were calculated to achieve overall stiffness values. The stiffness measurements in units of kilopascals $(\mathrm{kPa})$ were displayed as average stiffness, median stiffness, minimum and maximum stiffnesses, and standard deviation (SD). The stiffness images were displayed in color where red color represented high stiffness and a dark purple color represented no stiffness.

\section{Imaging interpretation}

Two abdominal radiologists with 9 and 23 years of experience reviewed MRI and MRE images by consensus. Both radiologists were blinded to stiffness values.

The axial thin-slice T2W images through the whole prostate gland were used to determine the components of $\mathrm{BPH}$. The proportion of $\mathrm{BPH}$ was classified into three categories: (1) glandular predominate (glandular component $>50 \%$ ), (2) stromal predominate (stromal component $>50 \%$ ), and (3) equal glandular and stromal component. The BPH pattern was classified according to Randall's classification [10]. The dimensions and volumes of the prostate gland were measured and recorded in centimeters $(\mathrm{cm})$ and milliliter $(\mathrm{ml})$. Other findings seen on MR images such as hemorrhage or utricle cyst were also recorded.

For the MRE assessment, the number of acquired slices, mean stiffness with SD, minimum and maximum stiffness $(\mathrm{kPa})$ were recorded. The stiffness maps and $\mathrm{T} 2 \mathrm{~W}$ images were simultaneously interpreted to evaluate the components of $\mathrm{BPH}$ in the area of increased stiffness, which was defined by red or orange colors in the stiffness map.

\section{Statistical analysis}

Continuous data were demonstrated by their means and $\mathrm{SD}$, or median and interquartile range. Categorical data were demonstrated by number and proportion. Comparisons of numerical data between groups were analyzed by using a nonparametric test. The intraclass correlation coefficients (ICC) between the measurements of two MRE examinations to evaluate reproducibility were done. The level of significance was set at $p<0.05$.

\section{Results}

Eight patients had PI-RADS scores of 2 and two patients had PI-RADS scores of $2 / 3$ due to disagreement between two reviewers. None of them had a PI-RADS score of 1. Baseline characteristics are displayed in Table 3. The average PSA level was $11.85 \mathrm{ng} / \mathrm{ml}$ (SD 8.43, range 2.11$26.70 \mathrm{ng} / \mathrm{ml})$. The average volume of a prostate gland was 


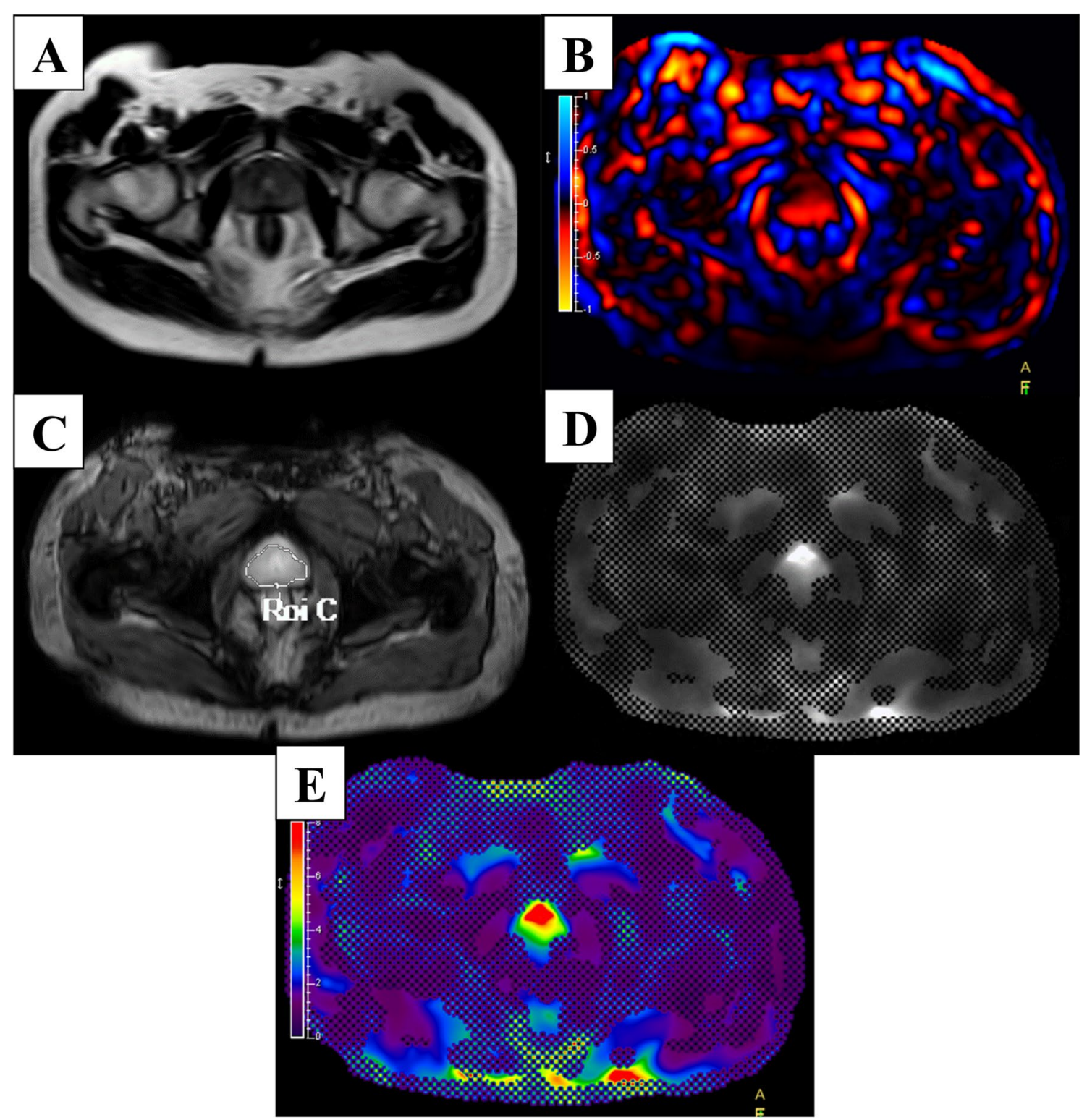

Fig. 1 Demonstrating MRE images in one same slice. A T2W image. B Wave image. C FFE image. D Modulus image. E Stiffness image

$90.1 \mathrm{ml}$ (SD 61.82, range 51.21-239.73 $\mathrm{ml}$ ). There was a significant correlation between the PSA level and the volume of the prostate gland with a moderate positive correlation $(r=0.590 ; p=0.021)$. The PSA level had no significant correlation with the prostate height $(p=0.383)$ or proportion of $\mathrm{BPH}(p=0.237)$. Two patients underwent biparameter MRI (bpMRI) and eight patients underwent multiparameter MRI (mpMRI) before MRE examination. All subjects tolerated the mechanical vibration and scan protocol well. None had any complications from the MRI/MRE examination. The MRE examination time in each patient was less than $20 \mathrm{~min}$.
From T2W images, there were four patients with a predominant glandular component, three patients with predominant stromal component, and three patients with equal glandular-stromal component. Nine patients had bilateral $\mathrm{TZ}$ and a retrourethral enlargement pattern (type 3 ) and only one patient had a pedunculated, bilateral TZ and retrourethral enlargement pattern (type 5) (Table 4).

The mean stiffness of the whole prostate gland was $4.40 \mathrm{kPa}$ (SD 0.71, min 3.35, $\max 5.96 \mathrm{kPa}$ ) (Table 5). Patients with glandular predomination tended to have lower maximal stiffness than stromal predomination or 


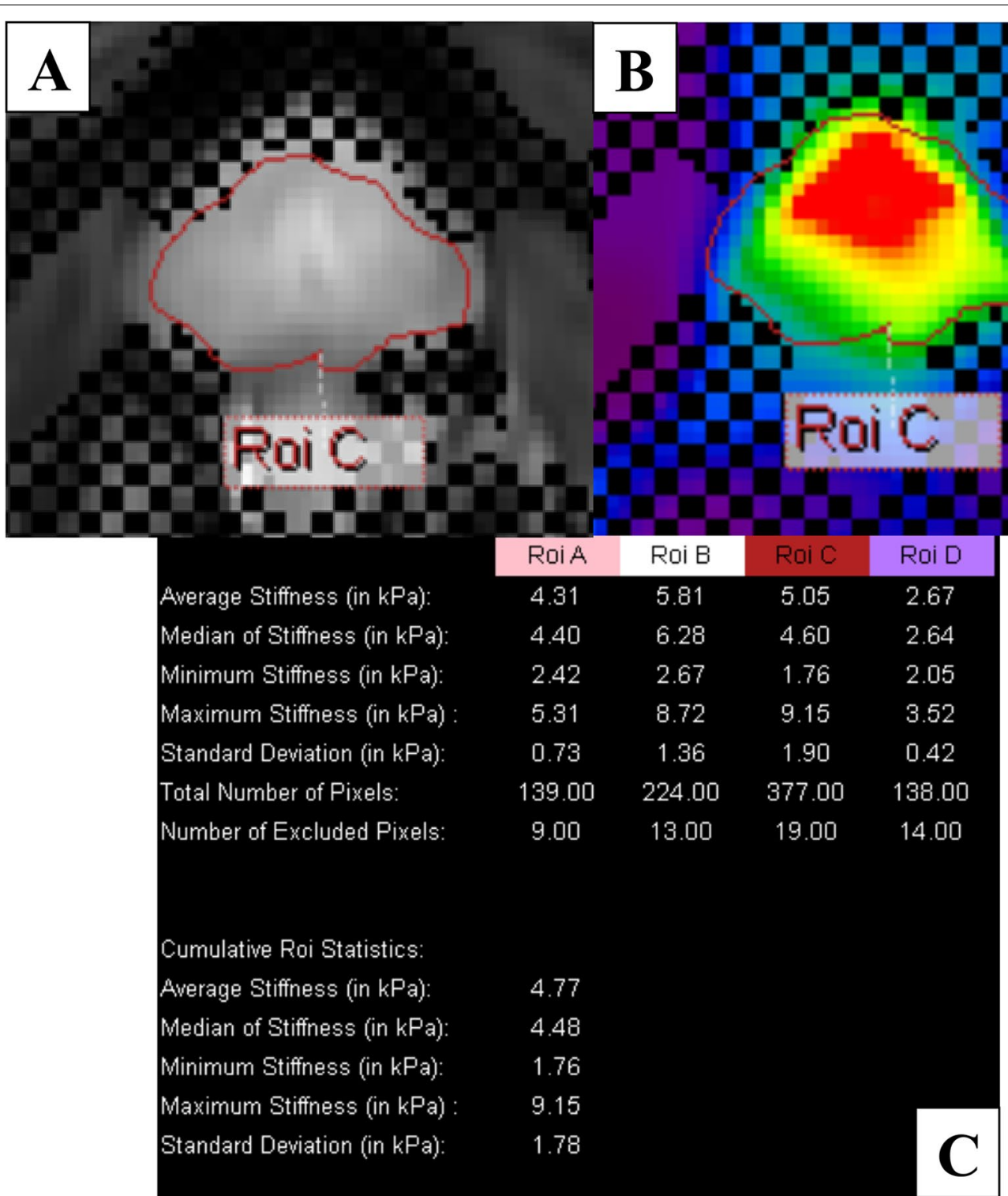

Fig. 2 Demonstrating the measurement method and documented results in post-processing software. A The ROI was drawn manually covering the entire prostate gland on the axial image. B ROI was also shown on the stiffness image. C Displayed stiffness values in each slice in average, median, minimum, maximum, and SD of stiffness with aggregate stiffness values

Table 3 Patient characteristics

\begin{tabular}{|c|c|c|c|c|c|c|}
\hline & $n$ & Average & SD & Min & Max & Median \\
\hline Age (year) & 10 & 70.6 & 10.4 & 57.0 & 91.0 & 70.5 \\
\hline $\mathrm{BMI}\left(\mathrm{kg} / \mathrm{m}^{2}\right)$ & 10 & 24.9 & 3.7 & 19.1 & 29.8 & 24.6 \\
\hline PSA level (ng/ml) & 10 & 11.85 & 8.43 & 2.11 & 26.70 & 9.74 \\
\hline Prostate width $(\mathrm{cm})$ & 10 & 5.72 & 0.73 & 4.84 & 7.11 & 5.60 \\
\hline Prostate height $(\mathrm{cm})$ & 10 & 6.11 & 1.97 & 4.53 & 10.99 & 5.34 \\
\hline Prostate AP (cm) & 10 & 4.53 & 0.78 & 3.71 & 5.90 & 4.23 \\
\hline Prostate volume (ml) & 10 & 90.1 & 61.8 & 51.2 & 239.7 & 65.7 \\
\hline $\operatorname{PSAD}\left(\mathrm{ng} / \mathrm{ml}^{2}\right)$ & 10 & 0.14 & 0.08 & 0.03 & 0.33 & 0.16 \\
\hline
\end{tabular}


equal glandular-stromal components $(p=0.317$ in first MRE and 0.035 in second MRE) (Fig. 3). There were no significant relationships between the average, median and minimal stiffness and different types of BPH. It was found that only one patient (No\#4) had different acquired slices, four slices in first MRE and three slices in second MRE. There was an excellent correlation between the number of slices in first and second MREs $(r=0.93 ; p=0.001)$. The number of acquired slices correlated with the height of the prostate gland. The group of 1-3 slices-acquired had an average prostate height of $4.90 \pm 0.41 \mathrm{~cm}$ and the group of more than three slices-acquired had an average prostate height of $6.42 \pm 3.46 \mathrm{~cm}(p=0.08$ for the first MRE and $p=0.01$ for the second MRE). There were 87 areas of increased stiffness on stiffness images (43 from first MRE and 44 from second MRE). Forty-four areas (50.6\%, 22 from first MRE and 22 from second MRE) corresponded to a stromal component on T2W images. Thirty-three areas (37.9\%, 16 from first MRE and 17 from second MRE) corresponded to mixed glandular and stromal components. There was one area that was seen only on the second MRE, whereas, other areas were the same areas as seen on the first MRE. There were only four areas (4.6\%, two from first MRE, and two from second MRE) that corresponded to the glandular component. Four areas in patient No\#2 (4.6\%, two from first MRE, and two from second MRE) corresponded to right and left central zones and two areas in the same patient (2.3\%, one from first MRE, and one from second MRE) corresponded to the urethra. All areas of increased stiffness seen on both first MRE and second MRE were the same areas in both examinations.

For analysis of test-retest reliability of tissue stiffness using ICC, it was found that mean stiffness had good overall reproducibility (ICC 0.82). Maximum stiffness (ICC 0.74) and SD of the stiffness (0.65) had moderate overall reproducibility. Minimum stiffness had poor reproducibility (ICC 0.42 ). For analysis of the reliability of number of acquired MRE slices and number of areas of increased stiffness on stiffness images, it was found that there was excellent reliability between the two examinations (ICC 0.93 and 0.99).

For per-patient results (Tables 4, 5), the patient No\#5 was the only one who had BPH type 5 . His MRI showed equal glandular-stromal components. He had the largest size of prostate gland $(239.7 \mathrm{ml})$, the highest number of acquired MRE slices (five slices), and the highest average tissue stiffness $(5.96 \mathrm{kPa})$. His PSA level was $11.0 \mathrm{ng} / \mathrm{ml}\left(\right.$ PSAD $0.04 \mathrm{ng} / \mathrm{ml}^{2}$ ).

Table 4 MRI features of all patients in the study

\begin{tabular}{|c|c|c|c|c|c|c|c|}
\hline No & Protocol & Proportion of BPH & Pattern of BPH & PIRADS & $\begin{array}{l}\text { Prostate } \\
\text { volume } \\
(\mathrm{ml})\end{array}$ & $\begin{array}{l}\text { PSA (ng/ml) } \\
\text { PSAD (ng/ } \\
\left.\mathrm{ml}^{2}\right)\end{array}$ & Other findings \\
\hline 1 & mpMRl & Glandular predominant & $\begin{array}{l}\text { Bilateral TZ and retrourethral } \\
\text { enlargement (type } 3 \text { ) }\end{array}$ & 2 & 63.4 & $\begin{array}{r}10.30 \\
0.16\end{array}$ & $\begin{array}{l}\text { Chronic prostatitis and scar at left } \\
\text { peripheral zone of mid gland }\end{array}$ \\
\hline 2 & mpMRI & Glandular predominant & $\begin{array}{l}\text { Bilateral TZ and retrourethral } \\
\text { enlargement (type } 3 \text { ) }\end{array}$ & $2 / 3$ & 53.1 & $\begin{array}{l}9.17 \\
0.17\end{array}$ & $\begin{array}{l}\text { Hemorrhage at right transition } \\
\text { zone of mid gland }(1.5 \times 1.2 \mathrm{~cm})\end{array}$ \\
\hline 3 & mpMRl & Glandular predominant & $\begin{array}{l}\text { Bilateral TZ and retrourethral } \\
\text { enlargement (type 3) }\end{array}$ & 2 & 68.1 & $\begin{array}{l}2.11 \\
0.03\end{array}$ & $\begin{array}{l}\text { Hemorrhage at left transition zone } \\
\text { of mid gland }(1.2 \times 0.3 \mathrm{~cm})\end{array}$ \\
\hline 4 & mpMRI & Stromal predominant & $\begin{array}{l}\text { Bilateral TZ and retrourethral } \\
\text { enlargement (type } 3 \text { ) }\end{array}$ & 2 & 58.7 & $\begin{array}{l}7.73 \\
0.13\end{array}$ & \\
\hline 5 & mpMRI & Equal & $\begin{array}{l}\text { Pedunculated with bilateral TZ } \\
\text { and retrourethral enlargement } \\
\text { (type 5) }\end{array}$ & $2 / 3$ & 239.7 & $\begin{array}{r}11.04 \\
0.04\end{array}$ & $\begin{array}{l}\text { A } 0.8-\mathrm{cm} \text { prostatic utricle cyst } \\
\text { with internal hemorrhage/high } \\
\text { proteinaceous content } \\
\text { Several calcification foci } \\
\text { A small area of hemorrhage at } \\
\text { right TZ of mid gland }\end{array}$ \\
\hline 6 & mpMRl & Equal & $\begin{array}{l}\text { Bilateral TZ and retrourethral } \\
\text { enlargement (type } 3 \text { ) }\end{array}$ & 2 & 72.5 & $\begin{array}{r}13.10 \\
0.18\end{array}$ & Minimal ascites in pelvic cavity \\
\hline 7 & bpMRI & Stromal predominant & $\begin{array}{l}\text { Bilateral TZ and retrourethral } \\
\text { enlargement (type } 3 \text { ) }\end{array}$ & 2 & 161.2 & $\begin{array}{r}26.70 \\
0.17\end{array}$ & Minimal ascites in pelvic cavity \\
\hline 8 & bpMRI & Equal & $\begin{array}{l}\text { Bilateral TZ and retrourethral } \\
\text { enlargement (type } 3 \text { ) }\end{array}$ & 2 & 51.3 & $\begin{array}{l}4.08 \\
0.08\end{array}$ & A prostatic utricle cyst $0.5 \mathrm{~cm}$ \\
\hline 9 & mpMRI & Glandular predominant & $\begin{array}{l}\text { Bilateral TZ and retrourethral } \\
\text { enlargement (type } 3 \text { ) }\end{array}$ & 2 & 51.2 & $\begin{array}{l}7.66 \\
0.15\end{array}$ & $\begin{array}{l}\text { A few small high SI foci on T1W; } \\
\text { probably calcification, high-pro- } \\
\text { teinaceous content or hemorrhage }\end{array}$ \\
\hline 10 & mpMRl & Stromal predominant & $\begin{array}{l}\text { Bilateral TZ and retrourethral } \\
\text { enlargement (type 3) }\end{array}$ & 2 & 81.5 & $\begin{array}{r}26.60 \\
0.33\end{array}$ & Minimal ascites in pelvic cavity \\
\hline
\end{tabular}




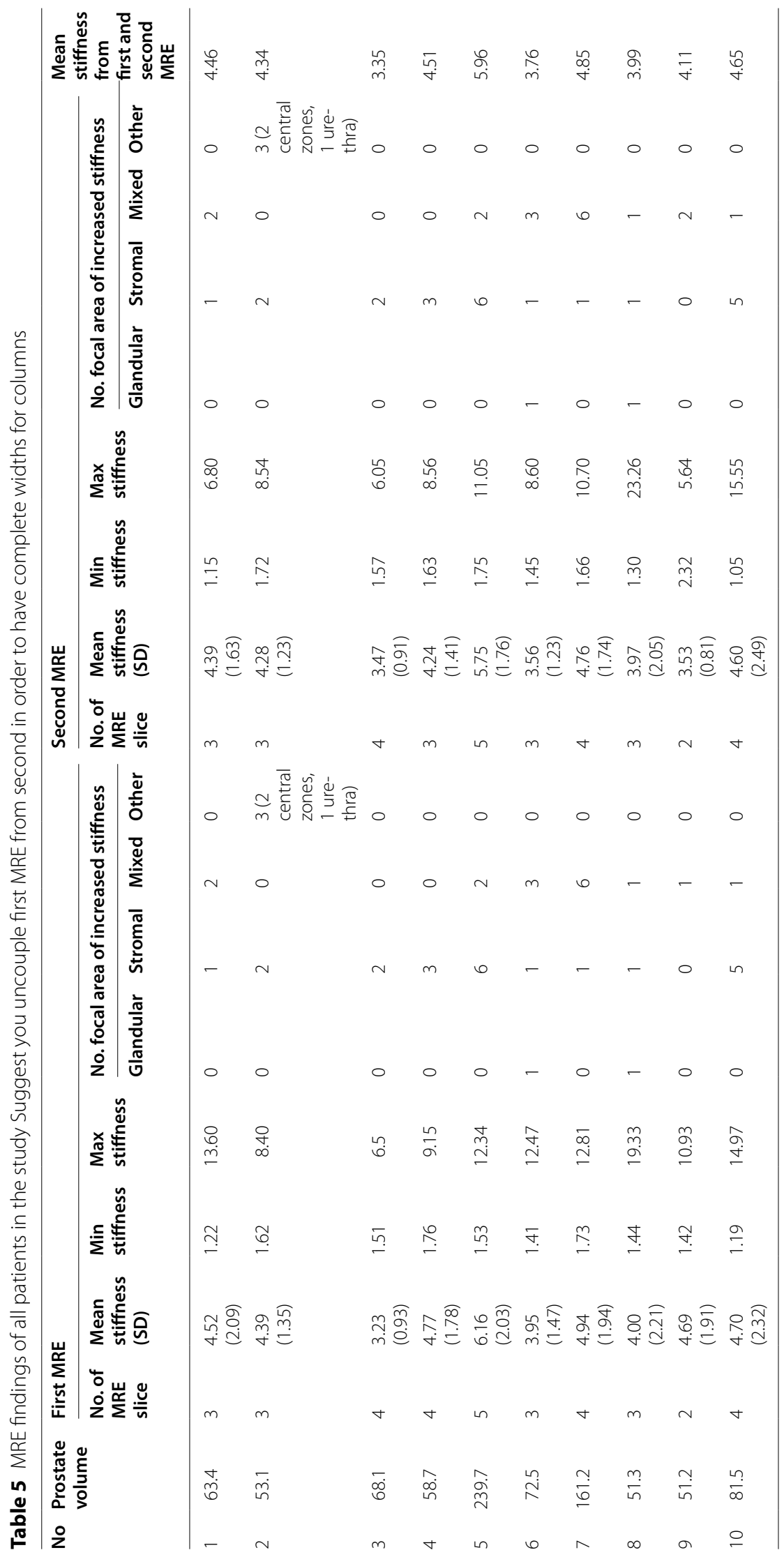




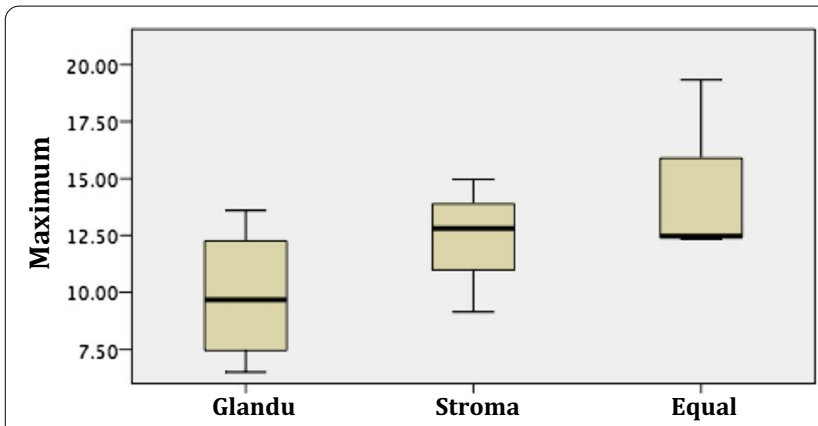

A

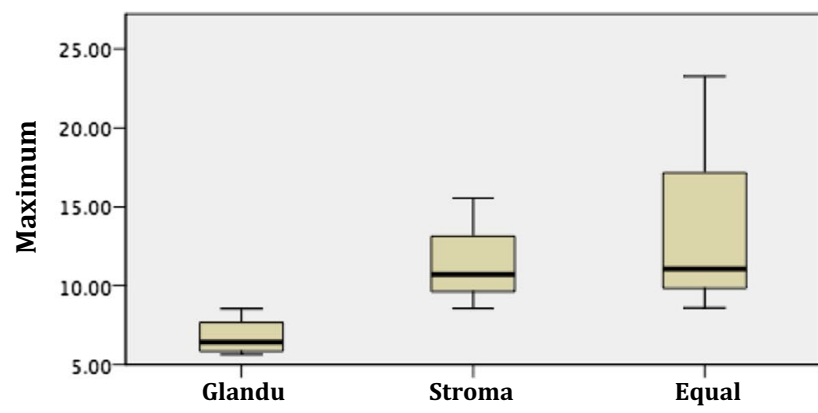

B

Fig. 3 Demonstrating correlation of the maximum stiffness ( $\mathrm{KPa}$ ) between each predominated proportion of BPH in $\mathbf{A}$ first MRE $\mathbf{B}$ second MRE

Patient No\#10 had the highest PSA and PSAD levels, $26.6 \mathrm{ng} / \mathrm{ml}$ and $0.33 \mathrm{ng} / \mathrm{ml}^{2}$. He had the third-largest size of prostate gland $(81.5 \mathrm{ml})$ and the third-highest average tissue stiffness $(4.65 \mathrm{kPa})$. He had a $\mathrm{BPH}$ with type 3 and a predominant stromal component.

Patient No\#3 had the lowest PSA $(2.11 \mathrm{ng} / \mathrm{ml})$ and PSAD $\left(0.03 \mathrm{ng} / \mathrm{ml}^{2}\right)$ levels. He had the lowest tissue stiffness too.

Patient No $\# 9$ had the lowest number of acquired slices and the smallest size of prostate gland, $51.2 \mathrm{ml}$.

\section{Discussion}

This study showed that the MRE of the prostate gland using an external air driver with a frequency of $60 \mathrm{~Hz}$ is successful in evaluating tissue stiffness. All ten patients could well tolerate the mechanical vibration of the driver without any complications. This implies that the MRE of the prostate gland is a safe noninvasive method that could be added to conventional MRI. It was also possible to obtain the wave images which passed through the prostate gland and measured the tissue stiffness from the MRE examinations of all ten patients.

The mean tissue stiffness of the whole prostate gland in this study was $4.40 \pm 0.71 \mathrm{kPa}$ when compared with the previous MRE studies of J. Kemper et al. [12] He performed MRE using an external driver attached to the pubic bone by a $1.5 \mathrm{~T}$ scanner in seven healthy volunteers at a vibration frequency of $85 \mathrm{~Hz}$ and reported the mean values of elasticity inside the peripheral zone and central zone that were $3.3 \pm 0.5 \mathrm{kPa}$ and $2.2 \pm 0.3 \mathrm{kPa}$, which were lower than the current study stiffness mean value. After that Sahebjavaher et al. studied MRE using a $3.0 \mathrm{~T}$ scanner transperineal electromechanical transducer at a frequency of $70 \mathrm{~Hz}$ in six healthy volunteers and found mean shear stiffnesses of $11.5 \pm 2.9,13.8 \pm 4.5$ and $13.2 \pm 5.0 \mathrm{kPa}$ for the peripheral, central and transition zones [13]. That study showed a much higher value of stiffness than in this present study, although the study was performed in healthy volunteers. This might be caused by the different electromechanical transducer in this study and an air driver as in the current study, a different wave frequency and different setting of volunteers. The recent study of prostate MRE was performed by Dittmann $\mathrm{F}$ et al. to assess the elasticity of prostate gland in 12 healthy volunteers using a $1.5 \mathrm{~T}$ scanner with MRE and three externally placed pressurized-air drivers at vibration frequencies of 60,70 , and $80 \mathrm{~Hz}$. They found the shear wave speed of the entire prostate gland at a frequency of $60 \mathrm{~Hz}$ was $2.21 \pm 0.22 \mathrm{~m} / \mathrm{s}$ and there was no significant differences of values of shear wave speed between the peripheral zone $(2.23 \pm 0.20 \mathrm{~m} / \mathrm{s})$ and the central gland $(2.18 \pm 0.26 \mathrm{~m} / \mathrm{s})$ [14]. The shear wave speed $\left(V_{s}\right)$ to shear modulus ( $\mu$, reported in $\mathrm{kPa}$ ) conversion using the equation $\mu=\rho V_{s}^{2}(\rho=$ soft tissue density, assumed to be $1,000 \mathrm{~kg} / \mathrm{m}^{3}$ ) was used. So the mean stiffness values of the entire prostate gland, peripheral zone, and central gland from Dittmann's study were 5.02, 4.97, and $4.75 \mathrm{kPa}$, which were slightly higher than in the present study. There were limitations to compare the results of the current study to other previous studies due to differences in MR scanner, MRE hardware, protocol, technique, population, and post-processing software. From the present results, it can be recommended that further studies to evaluate the reliability of MRE in different settings should be done.

For evaluation of test-retest reliability without repositioning of patients and driver, this study achieved good reproducibility (ICC 0.82) for mean stiffness and moderate reproducibility for maximum and SD of stiffness (ICC 0.74 and 0.65). Minimum stiffness had poor reproducibility (ICC 0.42 ). The different values between two tests might be caused by inhomogeneous waves traversing the prostate gland which was is a small organ located deeply in the pelvis and the movement of 
adjacent organs such as bowel peristalsis which might affect imaging acquisition. Excellent reproducibility was found for several acquired MRE slices (ICC 0.93) which mainly depended on the size of prostate gland, especially the prostate height. For analysis of the number of areas of increased stiffness on stiffness images, this study also found excellent reliability between two examinations (ICC 0.99). The study, however, did not reposition the subjects and actuators which might induce small changes in wave patterns and wave amplitudes. As the result of reproducibility analysis in the study of Dittmann F et al., they found good test-retest reproducibility despite repositioning of subjects and actuators between measurements $(\mathrm{ICC}=0.88$ and 0.78 in the central gland and peripheral zone) [14].

For the analysis of MRI findings, there was a nearly equal proportion of $\mathrm{BPH}$ components in this study; four patients with predominated glandular component, three patients with predominated stromal component, and three patients with equal glandular and stromal components. Most patients (90\%) had a bilateral TZ and retrourethral enlargement pattern (type 3) and only one patient (10\%) had a pedunculated with bilateral TZ and retrourethral enlargement pattern (type 5). These results were potentially the same as the Randall et al. classification [11]. There were no patients with another pattern of $\mathrm{BPH}$ in this study which might be caused by too small a population in the study.

For the analysis of focal areas of increased stiffness seen on stiffness images, about half of them (50.6\%) corresponded to a stromal component on $\mathrm{T} 2 \mathrm{~W}$ images and more than one-third (37.9\%) correspond to mixed glandular and stromal components. Additionally, it was found that the glandular predominant group tended to have a lower maximal stiffness than when stromal predominant or equal in its glandular-stromal component. These results supported the review of Wasserman et al. [4] that the stromal component in $\mathrm{BPH}$ leads to an increased resistance of prostatic parenchyma causing an increase in tissue stiffness.

Most other findings found in MRI were minimal ascites in the pelvic cavity, a small area of hemorrhage in the prostate gland and small prostatic utricle cysts which were not corresponding to areas of increased stiffness on stiffness images. Therefore, it can be assumed that these findings might not cause an increase in tissue stiffness. The study found, however, that some features which were seen on patients with high mean stiffness values including prostatic calcification, type- $5 \mathrm{BPH}$ pattern and the large prostate volume, it was possible to make an hypothesis that these features might be associated with an increase in tissue stiffness. Further study with more subjects would give more information about this hypothesis.
To the best of our knowledge, this study is the first study to exclusively describe MRE of the prostate gland in Thailand. There are several limitations to the study. Firstly, the study was a prospective study which had too small a number of subjects. Patients recruited into the study were less than was expected because of the Covid19 situation in the country. Secondly, there might be a selection biases especially in the population-based selection from $\mathrm{BPH}$ patients with high PSA levels who were requested to have an MRI to screen for prostate cancer. Other patients with $\mathrm{BPH}$ may have more findings. Thirdly, the study had no healthy volunteers to compare the results with which would make a more reliable study. Fourthly, it did not demonstrate the pathological diagnosis which is the gold standard for diagnosis of $\mathrm{BPH}$ and its correlation to MRI and MRE findings. Lastly, it tried to perform prostate MRE using the drivers and postprocessing software which were developed for measuring stiffness in the liver for the staging of liver fibrosis. The protocol might not be suitable for measuring stiffness in prostate gland so the results in the study might not represent valid tissue stiffness values. It is believed, however, that the results of the study would be beneficial for the development of an MRE protocol as an additional diagnostic tool for evaluating prostate disease and a guide to study more about prostate MRE in the future.

\section{Conclusions}

Prostate MRE is a useful noninvasive reproducible diagnostic tool for evaluating prostate tissue stiffness in both qualitative and quantitative assessments. The mean prostate tissue stiffness from MRE in patients with benign prostatic enlargement in this study was $4.40 \pm 0.71 \mathrm{kPa}$. Some MRI features might be associated with increased tissue stiffness.

\section{Abbreviations \\ BPH: Benign prostatic hyperplasia; FFE: Fast field echo; ICC: Interclass cor- relation coefficient; MRE: Magnetic resonance elastography; MRI: Magnetic resonance imaging; PI-RADS: Prostate imaging reporting and data system; PSA: Prostatic specific antigen; TZ: Transition zone.}

\section{Acknowledgements}

Ms. Kaewjai Thepsuthammarat for data management and bio-statistical analysis. Professor Richard L Ehman, Research Center, Mayo Clinic (Rochester, Minnesota) for his assistance with technical support under a Memorandum of Understanding (MOU) with Khon Kaen University. Emeritus Professor James A. Will, University of Wisconsin-Madison for editing the manuscript via Publication clinic KKU, Thailand.

\section{Authors' contributions}

CA: conceptualization, methodology, validation, resources, writing review and editing, project administration. WK: methodology, validation, writing review and editing. KE: methodology, investigation, data curation, writing original draft. PT: investigation, validation. SJ: data collection, validation. All authors read and approved the final manuscript. 


\section{Funding}

This research did not receive any specific grant from funding agencies in the public, commercial, or not-for-profit sectors.

\section{Availability of data and materials}

All data and material in this study are available to your request.

\section{Declarations}

Ethics approval and consent to participate

This study was approved by the Khon Kaen University Ethics Committee for Human Research based on the Declaration of Helsinki and the ICH Good Clinical Practice Guidelines with reference number HE621470.

\section{Consent for publication}

Not applicable.

\section{Competing interests}

None.

Received: 27 October 2021 Accepted: 9 December 2021

Published online: 13 December 2021

\section{References}

1. Berry SJ, Coffey DS, Walsh PC, Ewing LL (1984) The development of human benign prostatic hyperplasia with age. J Urol 132:474-479

2. McVary K (2006) BPH: epidemiology and comorbidities. Am J Manag Care 5:S122

3. Marks LS, Treiger B, Dorey FJ, Fu YS, de Kernion JB (1996) Morphology of the prostate: distribution of tissue components in hyperplastic glands. Urology 44:486-492

4. Wasserman NF (2006) Benign prostatic hyperplasia: a review and ultrasound classification. Radiol Clin N Am 44:689-710

5. Randall A (1931) Surgical pathology of prostatic obstructions. Williams \& Wilkins, Baltimore

6. Aarnink RG, de la Rosette JJ, Huynen AL, Giesen RJ, Debruyne FM, Wijkstra $H$ (1996) Standardized assessment to enhance the diagnostic value of prostate volume; part I: morphometry in patients with lower urinary tract symptoms. Prostate 29:317-326
7. Wasserman NF, Spilseth B, Golzarian J, Metzger GJ (2015) Use of MRI for lobar classification of benign prostatic hyperplasia: potential phenotypic biomarkers for research on treatment strategies. Am J Roentgenol 205:564-571

8. Turkbey B, Rosenkrantz A, Haider M, Padhani A, Villeirs G, Macura K et al (2019) Prostate imaging reporting and data system version 2.1:2019 update of prostate imaging reporting and data system version 2. Eur Urol 76:340-351

9. Grossfeld GD, Coakley FV (2000) Benign prostatic hyperplasia: clinical overview and value of diagnostic imaging. Radiol Clin N Am 38:31-47

10. Guneyli S, Ward E, Thomas S, Yousuf AN, Trilisky I, Peng Y et al (2016) Magnetic resonance imaging of benign prostatic hyperplasia. Diagn Interv Radiol 22:215-219

11. Low G, Kruse SA, Lomas DJ (2016) General review of magnetic resonance elastography. World J Radiol 8:59-72

12. Kruse SA, Rose GH, Glaser KJ, Manduca A, Felmlee JP, Jack CR, Ehman $\mathrm{RL}$ (2008) Magnetic resonance elastography of the brain. Neuroimage 39:231-237

13. Ringleb SI, Bensamoun SF, Chen Q, Manduca A, An KN, Ehman RL (2007) Applications of magnetic resonance elastography to healthy and pathologic skeletal muscle. J Magn Reson Imaging 25:301-309

14. Lorenzen J, Sinkus R, Schrader D, Lorenzen M, Leussler C, Dargatz M, Röschmann P (2001) Imaging of breast tumors using MR elastography. Rofo 173:12-17

15. Kemper J, Sinkus R, Lorenzen J, Nolte-Ernsting C, Stork A, Adam G (2004) MR elastography of the prostate: initial in-vivo application. Rofo 176:1094-1099

16. Sahebjavaher RS, Nir G, Honarvar M et al (2015) MR elastography of prostate cancer: quantitative comparison with histopathology and repeatability of methods. NMR Biomed 28:124-139

17. Dittmann F, Reiter R, Guo J, Haas M, Asbach P, Fischer T et al (2018) Tomoelastography of the prostate using multifrequency MR elastography and externally placed pressurized-air drivers. Magn Reson Med 79:1325-1333

\section{Publisher's Note}

Springer Nature remains neutral with regard to jurisdictional claims in published maps and institutional affiliations.

\section{Submit your manuscript to a SpringerOpen ${ }^{\circ}$ journal and benefit from:}

- Convenient online submission

- Rigorous peer review

- Open access: articles freely available online

- High visibility within the field

- Retaining the copyright to your article

Submit your next manuscript at $\boldsymbol{\Delta}$ springeropen.com 